\title{
Co-aminobenzamid@AI-SBA-15: a favorable catalyst in synthesis of 2,3-dihydroquinazolin-4(1H)-ones
}

\author{
Javad Safaei-Ghomi ${ }^{*}$, Raheleh Teymuri and Atefeh Bakhtiari
}

\begin{abstract}
The novel hybrid Co-aminobenzamid@Al-SBA-15 was synthesized as a modified mesoporous catalyst. To achieve this aim, the obtained materials were investigated by various techniques including Fourier transform infrared spectroscopy (FT-IR), X-ray diffraction (XRD), $N_{2}$ adsorption-desorption, field emission scanning electron microscopy (FE-SEM) and transmission electron microscopy (TEM) to examine the functional groups, crystallinity, surface area, morphology, particle size distribution and amounts of functional groups, respectively. Co-aminobenzamid@Al-SBA-15 exhibits excellent catalytic activity for the synthesis of 2,3-dihydroquinazolin-4(1H)-ones under mild reaction conditions. The heterogeneous catalyst showed good recyclability and can be reused for ten consecutive cycles without significant loss of its catalytic activity.
\end{abstract}

Keywords: Modified mesoporous, Aluminosilicate, Dihydroquinazolinones, Three-component condensation

\section{Introduction}

Nitrogen-containing fused-heterocycles are an integral part of biological and small molecule drugs or synthetic molecules [1] and physiologically active natural products [2]. Noteworthy, one of this fused-heterocycle is 2,3-dihydroquinazolinone (DHQZ-1) which contains wide pharmacological properties including anti-inflammatory, antibacterial, antitumor, and anticonvulsant [3-6]. Having looked at this importance, various catalysts were employed including, $\mathrm{KAl}\left(\mathrm{SO}_{4}\right)_{2} \cdot 12 \mathrm{H}_{2} \mathrm{O}$ [7], silica sulfuric acid (SSA) [8], aluminum methanesulfonate [9], $\mathrm{ZnO}$ nanoparticles [10], $\mathrm{Al}\left(\mathrm{H}_{2} \mathrm{PO}_{4}\right)_{3}[11]$, Montmorillonite K-10 [12], $\beta$-Cyclodextrin [13], $\mathrm{Co}(\mathrm{m}-\mathrm{NBS})_{2}$ [14]. Whereas the majority of these procedures have noticeable negative aspects such as long reaction times, low yields, harsh reaction conditions, and use of expensive and toxic catalysts. Therefore, to avoid these limitations, the exploration of an efficient, easily available catalyst with high catalytic activity and short reaction times for the preparation of dihydroquinazolins is still favored.

\footnotetext{
${ }^{*}$ Correspondence: safaei@kashanu.ac.ir

Department of Organic Chemistry, Faculty of Chemistry, University
}

of Kashan, Kashan, P.O. Box 87317-51167, Iran
Ordered mesoporous silicas such as those of M41S, SBA-n, and MSU-X families discovered in the early 1990s have been regarded as an encouraging class of materials for separation and catalysis $[15,16]$. These materials serve as an unprecedented choice for such applications. In fact, they offer high specific surface areas, large and defined pore sizes, defined surface acidity, and excellent mechanical and thermal stability $[17,18]$. Moreover, the substituents such as aluminum, titanium, and zirconium can be incorporated into the silica framework to obtain materials for applications such as catalysis and ion exchange. Among the metal substituted mesoporous materials, aluminum-incorporated mesoporous materials have considerable potential in moderating acid-catalyzed reactions for large molecules [19-21]. A large number of research groups have sought new and novel approaches toward incorporating multiple functional groups onto heterogeneous catalysts, which can catalyze multistep reaction cascades in one system or work in a cooperative manner to alter the characteristics of a single reaction [22-24]. In the current work, the use of material with surface functional groups shows improved selectivity catalyst. Consequently, we synthesize the novel hybrid Coaminobenzamid@Al-SBA-15 by amino-functionalized 
<smiles>[R][R]c1ccc(C2Nc3ccccc3C(=O)N2c2ccc([R2])cc2)cc1</smiles>

Scheme 1 Co-aminobenzamid@Al-SBA-15 catalyzed the synthesis of 2,3-dihydroquinazolin-4(1H)-one derivatives

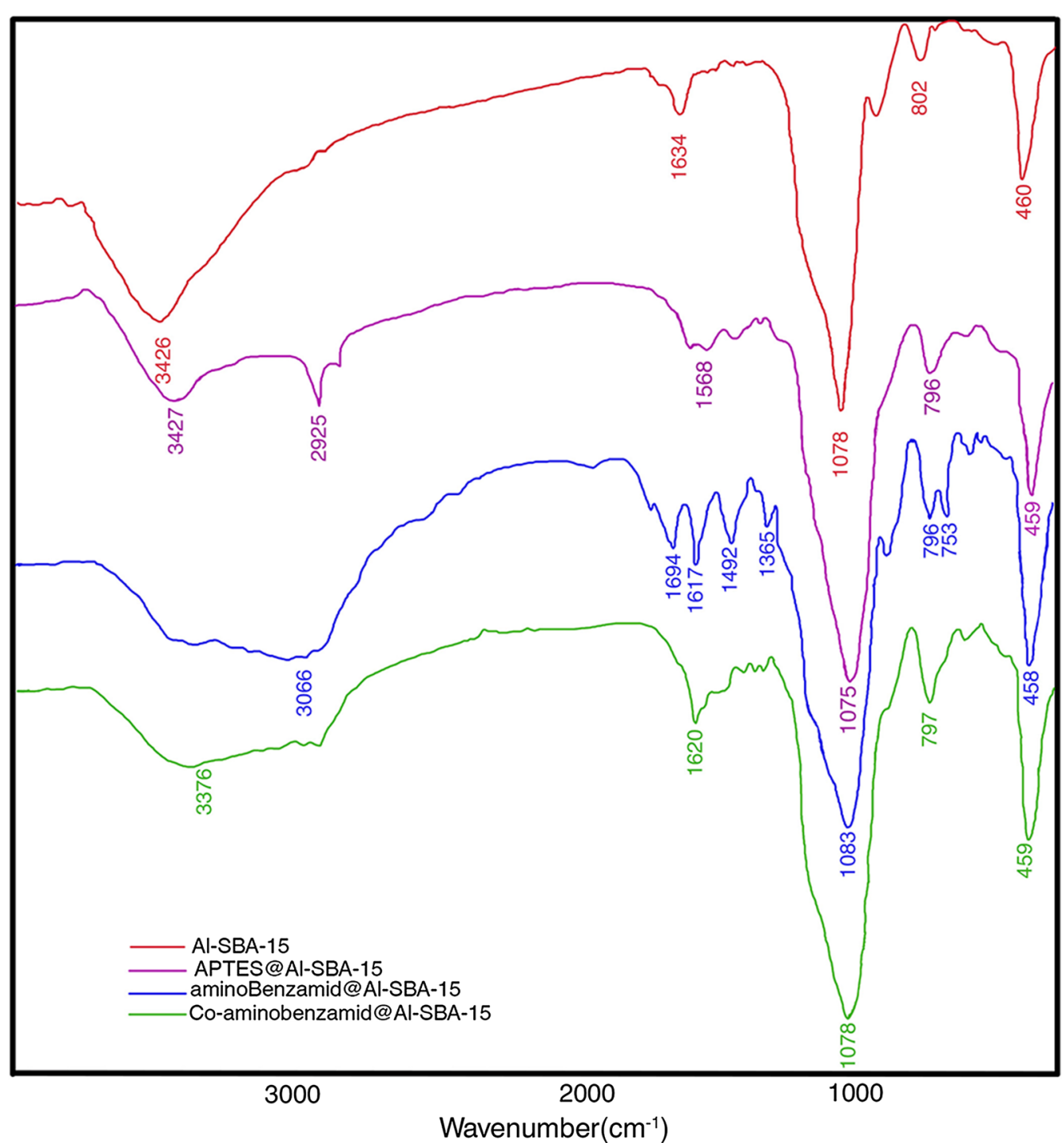

Fig. 1 Fourier-transform infrared (FT-IR) spectra of AI-SBA-15, ATPES@AI-SBA-15, aminobenzamid@AI-SBA-15, and Co-aminobenzamid@AI-SBA-15 


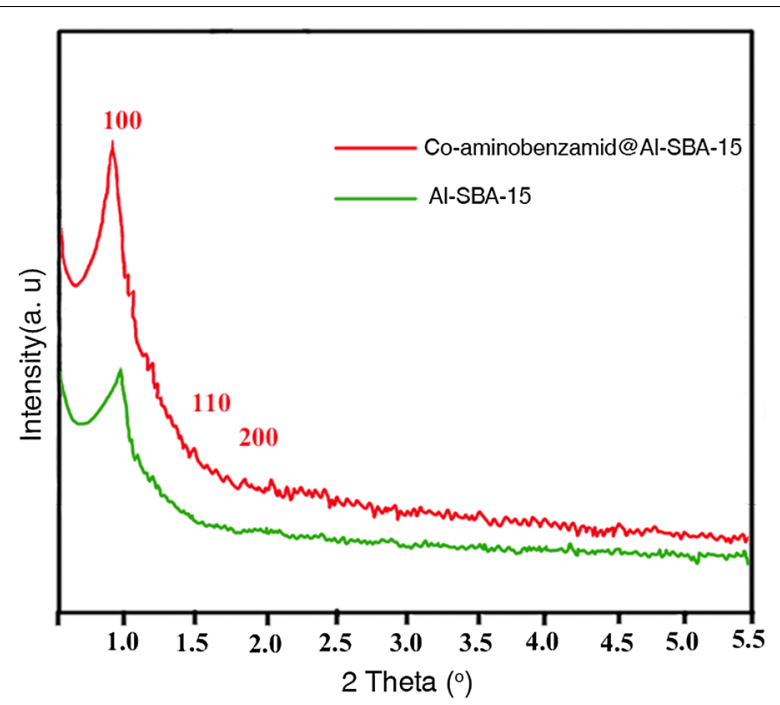

Fig. $2 \mathrm{~N}_{2}$ sorption isotherms of Al-SBA-15, aminobenzamid@ Al-SBA-15, and Co-aminobenzamid@Al-SBA-15

with employing 3-aminopropyltriethoxysilane (3-APTES) and anchored 2-aminobenzamide on it. The synthesizing process pursued by grafting of $\mathrm{Co}$ (II) to catch the desired product. Also, the activity of catalyst has been scrutinized by synthesizing 2,3-dihydroquinazolin-4(1H)-one derivatives (Scheme 1).

\section{Results and discussion}

The Fourier-transform infrared (FT-IR) spectra of AlSBA-15, APTMS@Al-SBA-15, aminobenzamid@AlSBA-15, and Co-aminobenzamid@Al-SBA-15 are shown in Fig. 1 . The peaks at $600-1200 \mathrm{~cm}^{-1}$ can be attributed to the vibration of $\mathrm{Si}-\mathrm{O}$ groups in the mesoporous silica framework. The absorption bands of Al-SBA-15 based materials at 1078,802 , and $460 \mathrm{~cm}^{-1}$ are attributed to the $\mathrm{Si}-\mathrm{O}-\mathrm{Si}$ anti-stretching vibration, the $\mathrm{Si}-\mathrm{O}-\mathrm{Si}$ stretching vibration, and the bending vibration of $\mathrm{Si}-\mathrm{O}$, respectively. In the FT-IR spectrum of APTES@Al-SBA-15, there are the characteristic bands of $-\mathrm{NH}_{2}$ at $3427,1568 \mathrm{~cm}^{-1}$. For the aminobenzamid@Al-SBA-15 sample, the absorption peak at 1694, 1617 and $1494 \mathrm{~cm}^{-1}$ is observed and attributed to the characteristic peaks of aminobenzamid, due to the presence of the $\mathrm{C}=\mathrm{O}$ bonds. After aminobenzamid@Al-SBA-15 coordinated with Co, this IR absorption peak shifted from 1617 to $1620 \mathrm{~cm}^{-1}$, which is indicative for the formation of a Co-ligand bond. The results above imply the presence of aminobenzamid bonded on the surface of Al-SBA-15, and that the molecular structure of these functional moieties can be perfectly retained in the complex of Co-aminobenzamid@Al-SBA-15.

The $\mathrm{N}_{2}$ adsorption/desorption isotherms and pore-size distribution curves of the samples are displayed in Fig. 2. As shown in Fig. 2, all the isotherms exhibited a typical type IV isotherm with an H1 hysteresis loop starting from $\mathrm{P} / \mathrm{P}_{0}=0.6$. This is the characteristic of mesoporous Al-SBA-15 with ordered pore structures, which is quite important to disperse and stabilize the supported Cobalt species. Compared with the BET surface area $\left(815 \mathrm{~m}^{2} / \mathrm{g}\right)$ of Al-SBA-15, the surface area of Co-aminobenzamid@ Al-SBA-15 was decreased to $581 \mathrm{~m}^{2} / \mathrm{g}$ after Al-SBA- 15 was functionalized. The inset displays the narrow pore size distribution centered on 6.42, 4.27 and $3.94 \mathrm{~nm}$ for Al SBA-15, aminobenzamid@Al-SBA-15 and Co-aminobenzamid@Al-SBA-15 samples, respectively. Aminobenzamid@Al-SBA-15 displays a little smaller pore size than the parent Al-SBA-15 due to the incorporation of $\mathrm{Ph}$-groups and $\mathrm{NH}_{2}$ into the pore channels. These results are in excellent agreement with the fact that the surface of mesoporous Al-SBA-15 has been successfully modified by aminobenzamid. Co species have entered into the channels of the Al-SBA-15 materials, resulting in the decrease in its pore size.

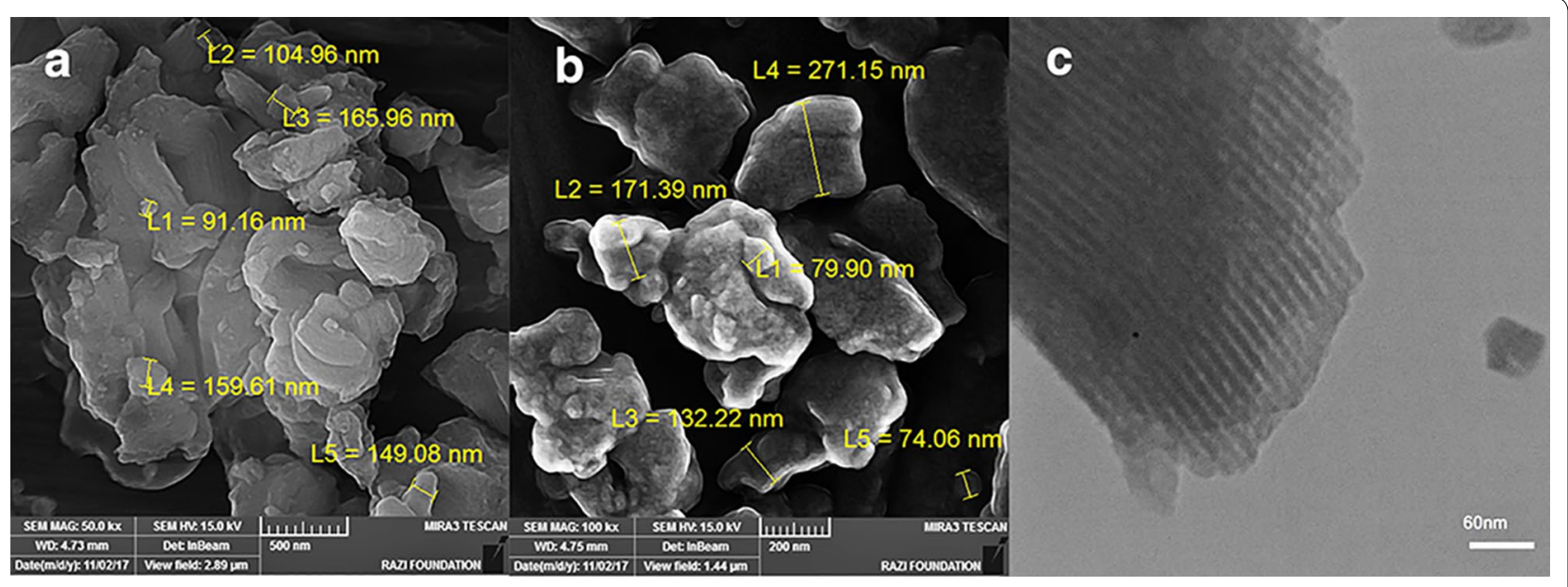

Fig. 3 FE-SEM images of a Al-SBA-15, b Co-aminobenzamid@AI-SBA-15 and TEM image of c Co-aminobenzamid@Al-SBA-15 
In order to obtain the morphology and particle size of nanoparticles, SEM images of the mesoporous were obtained and are presented in (Fig. 3). As shown in the SEM images, of Fig. 3a the Al-SBA-15 sample is that with the bagel-shaped particles with relatively uniform sizes. After being functionalized with aminobenzamid and Co the shape of Al-SBA-15 is unchanged noticeably (Fig. 3b). The TEM image of the Co-aminobenzamid@Al-SBA-15 sample (Fig. 3c) reveals that no cobalt can be observed in the pores, which shows the $\mathrm{Co}^{2+}$ ions have coordinated with two $\mathrm{N}$ atoms in aminobenzamid@Al-SBA-15.

The small-angle XRD patterns of Al-SBA-15 and Coaminobenzamid@Al-SBA-15 are shown in Fig. 4. The Bragg peaks in the $2 \mathrm{q}$ range of $0.8-2$, which can be indexed as (1 $\left.\begin{array}{lll}1 & 0\end{array}\right),\left(\begin{array}{lll}1 & 1 & 0\end{array}\right)$ and $\left(\begin{array}{lll}2 & 0 & 0\end{array}\right)$ reflections of the two-dimensional hexagonal structure of the SBA-15 material. As can be seen, the regularity of Al-SBA-15 is decreased. The ordered structure of Co-aminobenzamid@Al-SBA-15 has remained intact, as supported by the XRD results. Also, there is no major change in the crystallinity of Al-SBA-15 after functionalization and Co immobilization. Furthermore, the diffraction peaks of Co species cannot be detected, which also shows that the Co species were immobilized into the pore channels of $\mathrm{Al}$ SBA-15 in the atom dispersion, and no crystal Co species existed in the sample. The elemental composition of Co-aminobenzamid@Al-SBA-15 spinel nanocrystals was shown by the EDS spectrum (Fig. 5).

Elemental analysis results showed that the carbon, nitrogen, oxygen, aluminum, silicon, cobalt amount of the Co-aminobenzamid@Al-SBA-15 was 25.89, 7.27, 40.92, 1.28, 20.21, 4.43 (wt\%).

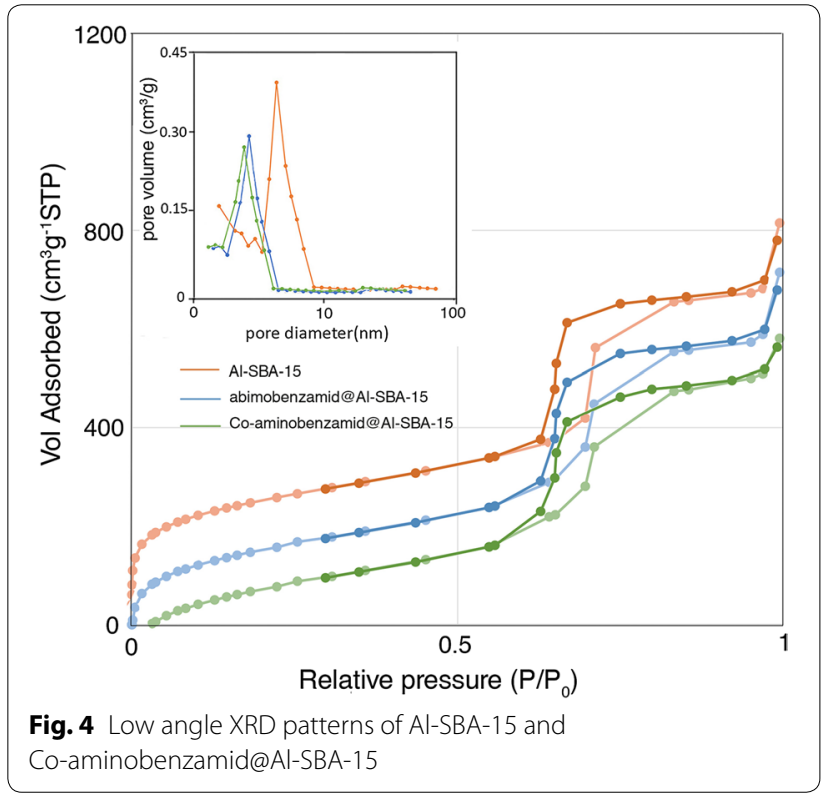

As a result of our great interest in preparation of heterocyclic compounds by applying heterogeneous catalysts $[25,26]$, herein we wish to report an efficient procedure to synthesize 2,3-dihydroquinazolin-4(1H)-one derivatives through a three-component one-pot condensation of isatoic anhydride, aromatic aldehyde and primary amines/or ammonium acetate using Co-aminobenzamid@Al-SBA-15 as catalyst (Scheme 1).

Beforehand, the reaction of isatoic anhydride, benzaldehyde and aniline were picked out as a model reaction. And now, the effect of experimental factors comprising the type and amount of catalyst and solvent were investigated to find the best condition for this reaction and the results are listed in Table 1. To begin with the solvent examination, it was demonstrated that $\mathrm{EtOH}$ is the most effective condition for this condensation of isatoic anhydride, aromatic aldehyde and primary amines or ammonium acetate (Table 1, entry 8 ). Also, amount of catalysts were investigated in the reaction of isatoic anhydride, benzaldehyde and aniline as listed in Table 1 . The highest yield was obtained by $0.03 \mathrm{~g}$ of Co-aminobenzamid@AlSBA-15 under reflux in $\mathrm{EtOH}$.

After optimization of the reaction conditions, to investigate the efficiency and the scope of the presented procedure, numerous mono and disubstituted 2,3-dihydroquinazolin-4(1H)-ones were formed via one-pot three-component condensation reactions between isatoic anhydride, aromatic aldehyde and primary amines/ or ammonium acetate using catalytic amounts of Coaminobenzamid@Al-SBA-15 under reflux conditions in ethanol (Tables 2,3).

To compare the efficiency of Co-aminobenzamid@AlSBA-15 with the reported catalysts for the synthesis of 2,3-dihydroquinazoline-4( $1 H)$-ones derivatives, we have tabulated the results in Table 4. As Table 4 indicates,

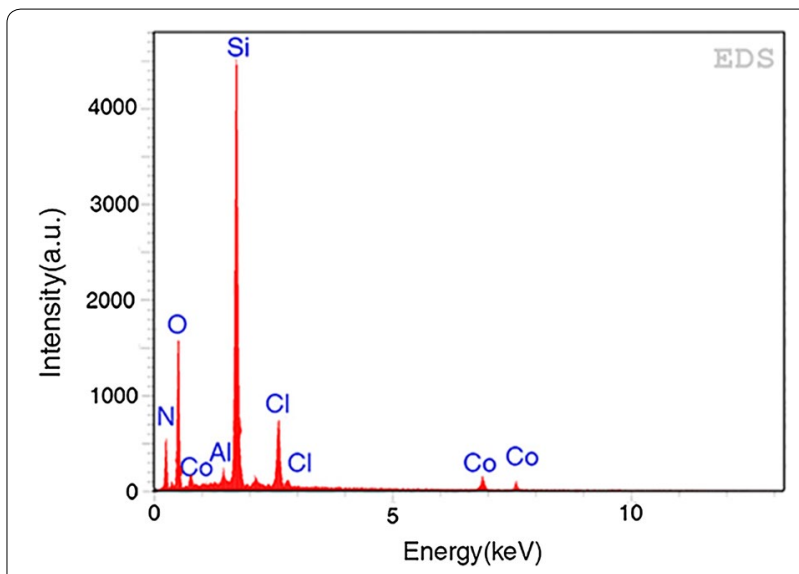

Fig. 5 Energy-dispersive X-ray spectroscopy of Co-aminobenzamid@ Al-SBA-15 
Table 1 The effect of reaction condition on the synthesis of 2,3-diphenyl-2,3-dihydroquinazolin-4(1H)-one under various conditions<smiles></smiles>

\begin{tabular}{|c|c|c|c|c|}
\hline Entry & Solvent (condition) & Catalyst & Time (min) & Yield $^{\mathrm{a}}(\%)$ \\
\hline 1 & Solvent-free & Co-aminobenzamid@Al-SBA-15 (0.03 g) & 80 & 40 \\
\hline 2 & Water (reflux) & Co-aminobenzamid@Al-SBA-15 (0.03 g) & 80 & 55 \\
\hline 3 & DCM (reflux) & Co-aminobenzamid@Al-SBA-15 (0.03 g) & 60 & Trace \\
\hline 4 & Acetone (reflux) & Co-aminobenzamid@Al-SBA-15 (0.03 g) & 60 & 25 \\
\hline 5 & Acetonitrile (reflux) & Co-aminobenzamid@Al-SBA-15 (0.03 g) & 90 & 30 \\
\hline 6 & Methanol (reflux) & Co-aminobenzamid@Al-SBA-15 (0.03 g) & 50 & 70 \\
\hline 7 & Ethanol (reflux) & Co-aminobenzamid@Al-SBA-15 (0.02 g) & 25 & 85 \\
\hline 8 & Ethanol (reflux) & Co-aminobenzamid@Al-SBA-15 (0.03 g) & 25 & 94 \\
\hline 9 & Ethanol (reflux) & Co-aminobenzamid@Al-SBA-15 (0.05 g) & 25 & 93 \\
\hline
\end{tabular}

a Isolated yields

Co-aminobenzamid@Al-SBA-15 is superior with respect to the reported catalysts in terms of reaction time, yield and conditions. In addition, our catalyst was recyclable for at least ten times. High catalytic activity and ease of recovery from the reaction mixture, and several reuse times without significant losses in performance are additional eco-friendly attributes of this catalytic system.

As a result of this table, condensation of aniline with commercially available aromatic aldehydes having electron-donating and electron withdrawing substituents produced $4 \mathrm{k}-\mathrm{t}$ in high yields (Table 3 , entries 1-10). According to the results, aldehydes bearing electrondonating groups produced the desired products more quickly than the aldehydes with electron-withdrawing groups. Though meta- and para substituted aromatic aldehydes reacted quickly, ortho substituted aromatic aldehydes give the product in longer reaction time (Table 2, entry 5, 6). Also, the results shown in Tables confirm that the reaction was compatible successfully with a broad range of substituents (both electron-donating and electron-withdrawing groups) in the amines or the aldehydes. All novel and known products were characterized by comparing their physical data, ${ }^{1} \mathrm{H},{ }^{13} \mathrm{CNMR}$, FT-IR spectroscopy, and elemental analysis spectra.

On the basis of the point mentioned above, a reasonable mechanism for the preparation of 2,3-dihydroquinazolin-4(1H)-ones derivatives by the Co-aminobenzamid@
Al-SBA-15 is suggested in Scheme 2. The first point, interaction of Co-aminobenzamid@Al-SBA-15 as a catalyst and isatoic anhydride to produce a reactive intermediate I. And now, the N-nucleophilic primary amine attacks on the carbonyl unit of I to produce a reactive intermediate II, which in turn affords III through decarboxylation reaction. Subsequently, the proton transfer of III affords 2-amino- $N$-substituted-amide IV. Besides the reaction of an activated aldehyde with IV proceeds to produce the imine intermediate $\mathrm{V}$. The part of amide functional group in intermediate IV could be formed using tautomerism phenomenon in the presence of the Co-aminobenzamid@Al-SBA-15. Accordingly, intermediate VI could be prepared by an intermolecular nucleophilic attack of the amide nitrogen on activated imine carbon, followed by a 1,5-proton transfer to yield the final 2,3-dihydroquin-azoline-4-(1H)-ones as the concluding product. These steps are efficiently carried out on the high nanoparticle surface and also by the cavitation effect of ultrasound irradiation. For the aforementioned mechanism, the significant roles of Co-aminobenzamid@ Al-SBA-15, are activation of carbonyl groups and efficient development of the reaction on its high surface area.

Another distinguishing feature of Co-aminobenzamid@Al-SBA-15 is recoverable without considerable loss of catalytic activity. In order to study the reusability of Co-aminobenzamid@Al-SBA-15 as an 
Table 2 Synthesis

of monosubstituted

2,3-

dihydroquinazoline-4(1H)-ones using Co-aminobenzamid @AI-SBA-15

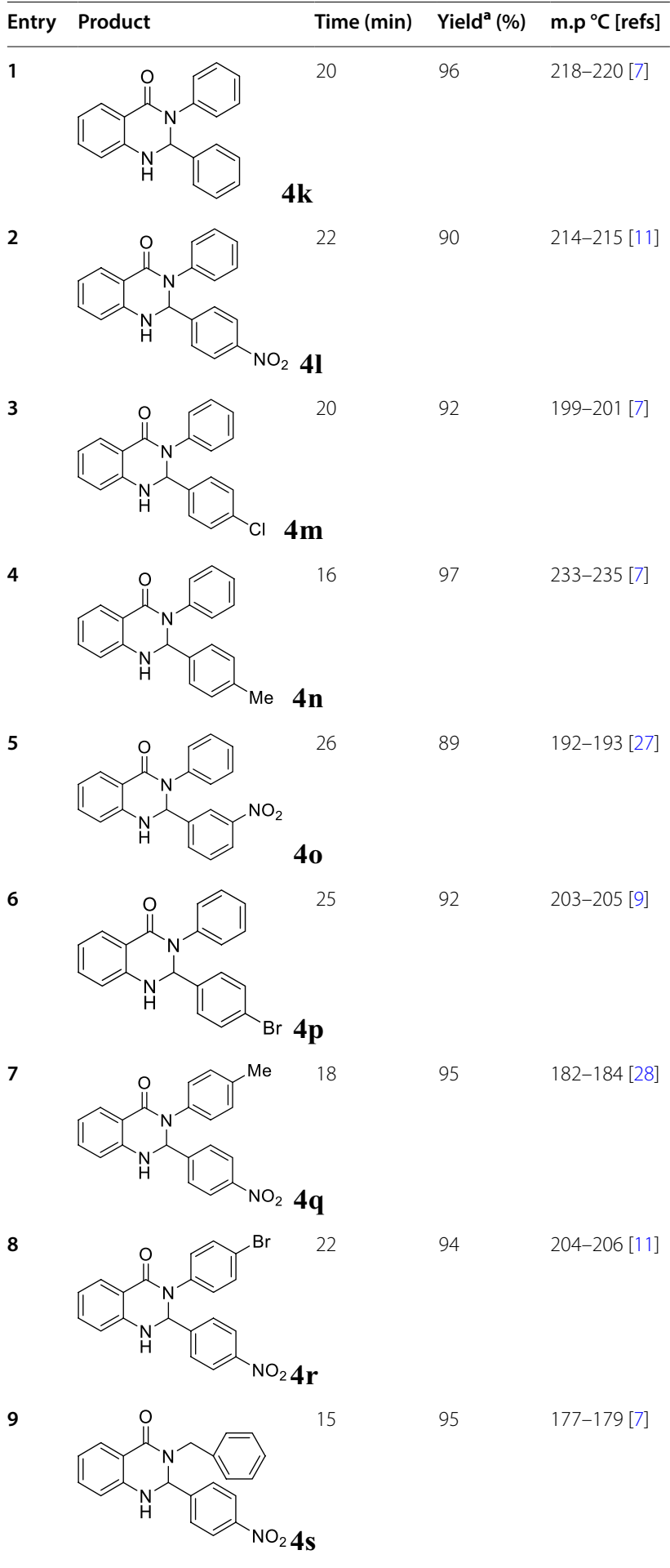

Table 2 (continued)

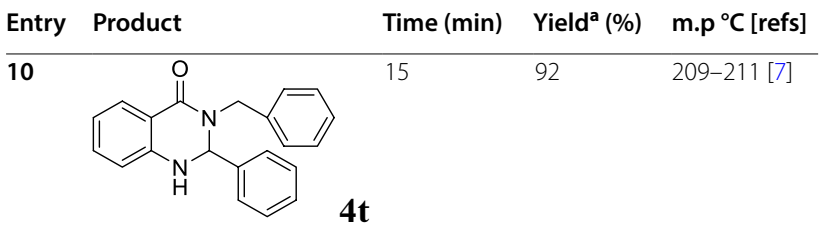

a Isolated yields

environmentally-friendly catalyst, at least ten batches of the experiments were carried out for the preparation of 2,3-diphenyl-2,3-dihydroquinazolin-4(1H)-one (4k). To prove this feature, after the accomplishment of the reaction, $5 \mathrm{~mL}$ ethanol was added to the reaction mixture and the modified mesoporous was recycled via filtration and washed Co-aminobenzamid@Al-SBA-15 was reused for the new condensation reaction of isatioc anhydride, benzaldehyde and aniline under similar reaction conditions up to ten cycles. There is an insignificant loss of catalytic activity and providing the products in high yield (Fig. 6).

\section{Conclusions}

To recapitulate briefly, we have reported a selective and efficient method for the synthesis of 2,3-dihydroquinazolin-4(1H)-ones derivatives via three-component one-pot condensation of isatoic anhydride, aromatic aldehyde and primary amines/or ammonium acetate using Coaminobenzamid@Al-SBA-15 as a novel catalyst. The current method provides obvious positive points such as environmental friendliness, significantly shorter reaction time, markedly excellent yields and simple workup procedure. In our opinion, we expect this method will find extensive applications in the field of combinatorial chemistry, diversity-oriented synthesis.

\section{Experimental section \\ General}

All organic materials were purchased commercially from Sigma-Aldrich, and Merck and were used without further purification. Melting points of products were determined by Electro thermal 9200. All IR spectra were recorded by means of FT-IR Magna spectrometer 550 Nicolet using $\mathrm{KBr}$ plates. NMR spectra were attained in DMSO- $d_{6}$ as a solvent and are reported as parts per million (ppm) downfield from TMS as an internal standard. The NMR spectra were obtained on a Bruker Avance- $400 \mathrm{MHz}$ spectrometer. HRMS analyses were carried out using a Bruker micro-TOF-Q-MS analyzer. The elemental analyses $(\mathrm{C}, \mathrm{H}, \mathrm{N})$ were obtained from a Carlo ERBA Model EA 1108 analyzer. The XRD patterns were recorded on an X-ray diffractometer (PHILIPS, PW 1510, Netherland) using $\mathrm{Cu}-\mathrm{K} \alpha$ radiation $(\lambda=0.154056 \mathrm{~nm})$ in the range $2 \theta=0.8-10^{\circ}$. Field 


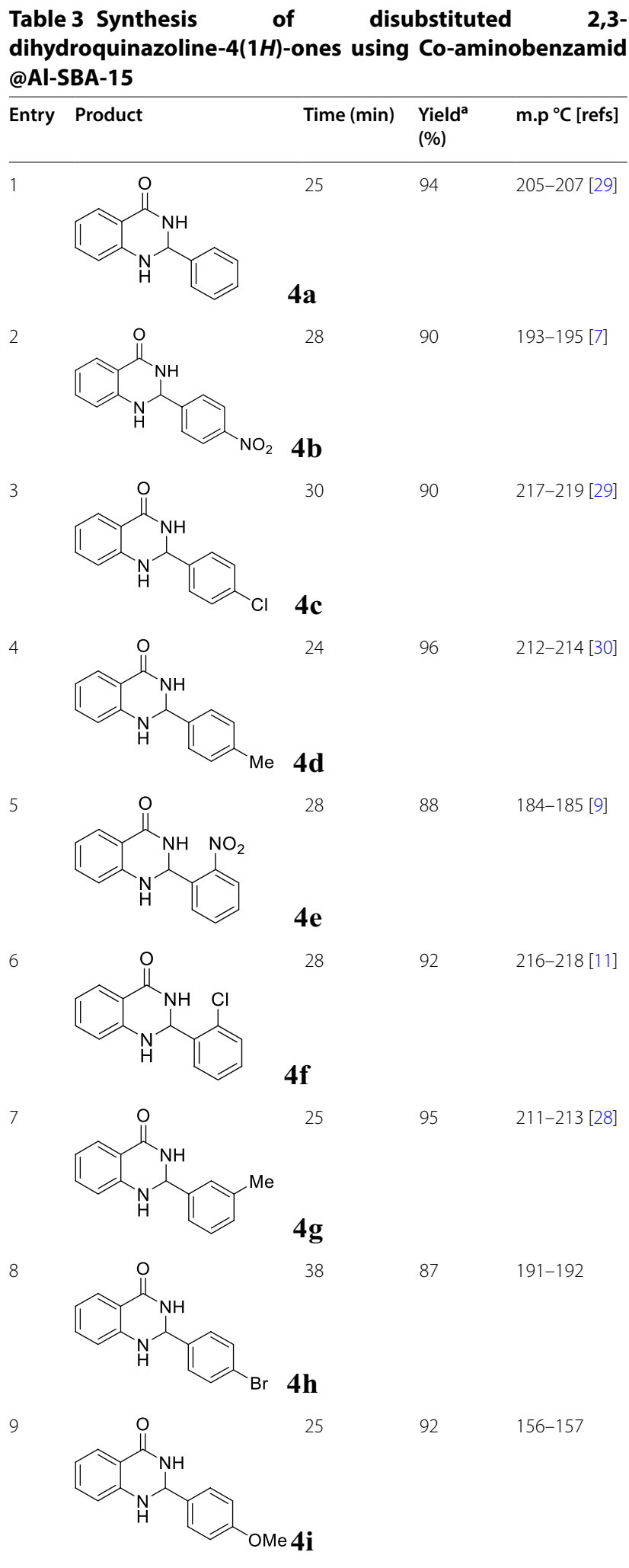

Table 2 (continued)

\begin{tabular}{llll}
\hline Entry Product & Time $(\min )$ & $\begin{array}{l}\text { Yield }^{\mathbf{a}} \\
(\%)\end{array}$ & m.p ${ }^{\circ} \mathrm{C}$ [refs] \\
\hline 10 & 23 & 94 & \\
\hline
\end{tabular}

a Isolated yields

Emission Scanning electron microscope (FE-SEM) of nanoparticles was performed on a Model FE-SEM. The particle size and structure were observed using a Philips CM10 transmission electron microscope operating at $30 \mathrm{kV}$. The $\mathrm{N}_{2}$ adsorption/desorption analysis (BET) was performed at $120{ }^{\circ} \mathrm{C}$ using an automated gas adsorption analyzer (BEL SORP mini II).

\section{Preparation of Al-SBA-15}

Al-SBA-15 were synthesized following published procedures [31, 32]. In a classic procedure $2 \mathrm{~g}$ of Pluronic P123 was dissolved in $75 \mathrm{~mL}$ hydrochloric acid solution of $\mathrm{pH}$ 1.5. The solution was stirred at $40{ }^{\circ} \mathrm{C}$ for $6 \mathrm{~h}$. A second solution was made by adding $3.2 \mathrm{~mL}$ of TEOS (tetraethylorthosilicate) and $5 \mathrm{ml}$ of the hydrochloric acid solution of $\mathrm{pH} 1.5$ to a $0.22 \mathrm{~g}$ of aluminum triisopropoxide. This suspension was vigorously stirred in a closed flask for $1.5 \mathrm{~h}$ during which it became clear. The TEOS solution was quickly added to the surfactant solution and stirred for $20 \mathrm{~h}$ at $40{ }^{\circ} \mathrm{C}$. The resulting clear suspension was transferred to a Teflon lined stainless steel autoclave and heated to $100{ }^{\circ} \mathrm{C}$ for $20 \mathrm{~h}$. The recovered white solid was filtrated and washed three times with demineralized water and two times with ethanol. The sample was dried overnight at $100{ }^{\circ} \mathrm{C}$. The template was removed by calcination for $10 \mathrm{~h}$ at $550^{\circ} \mathrm{C}$ with a heating ramp of $1{ }^{\circ} \mathrm{C} / \mathrm{min}$. The sample is designated as Al-SBA- 15 .

\section{Preparation of APTES@AI-SBA-15}

In a $50 \mathrm{~mL}$ three-necked round-bottomed flask, 3-aminopropyl triethoxysilane (APTES) $(1 \mathrm{~mL}, 5 \mathrm{mmol})$ was added dropwise to a suspension of Al-SBA-15 $(1 \mathrm{~g})$ in dry toluene $(30 \mathrm{~mL})$ under an $\mathrm{N}_{2}$ atmosphere. The mixture solution was refluxed for $24 \mathrm{~h}$. After that, the obtained solid was filtered and washed several times with dichloromethane to remove the unreacted starting material, and dried in a vacuum oven at $120^{\circ} \mathrm{C}$ for $8 \mathrm{~h}$. The white powder obtained was designated as APTES@Al-SBA-15. 
Table 4 Comparison of catalytic activity of Co-aminobenzamid@AI-SBA-15 with other reported catalysts

\begin{tabular}{|c|c|c|c|c|c|}
\hline Entry & Solvent (condition) & Catalyst & Time (min) & Yield $^{\mathrm{a}}(\%)$ & [Refs] \\
\hline 1 & Ethanol (reflux) & Co-aminobenzamid@Al-SBA-15 (0.03 g) & 25 & 94 & This work \\
\hline 2 & Ethanol (reflux) & Al-SBA-15 (0.03 g) & 45 & 80 & This work \\
\hline 3 & EtOH (reflux) & Montmorillonite K-10 (0.3 g) & 390 & 80 & {$[12]$} \\
\hline 4 & $\mathrm{H}_{2} \mathrm{O}$ (reflux) & $\beta$-Cyclodextrin (0.2\%) & 180 & 84 & {$[13]$} \\
\hline 5 & Ethanol/ $\mathrm{H}_{2} \mathrm{O}$ (reflux) & $\mathrm{Co}(\mathrm{m}-\mathrm{NBS})_{2}(3 \%)$ & 120 & 97 & {$[14]$} \\
\hline 6 & Ethanol (reflux) & $\mathrm{KAl}\left(\mathrm{SO}_{4}\right)_{2} \cdot 12 \mathrm{H}_{2} \mathrm{O}(0.5 \%)$ & 240 & 88 & {$[7]$} \\
\hline 7 & Solvent-free & Silica sulfuric acid (20\%) & 300 & 80 & {$[8]$} \\
\hline 8 & Solvent-free & $\mathrm{Al}\left(\mathrm{H}_{2} \mathrm{PO}_{4}\right)_{3}(16 \%)$ & 35 & 80 & {$[11]$} \\
\hline 9 & Solvent-free & Nano ZnO (20\%) & 180 & 88 & {$[10]$} \\
\hline
\end{tabular}

a Isolated yields

\section{Preparation of aminobenzamid@AI-SBA-15}

In a $50 \mathrm{~mL}$ round-bottomed flask, isatoic anhydride $(0.8 \mathrm{~g}, 5 \mathrm{mmol})$ was added to the suspension of APTES@ Al-SBA-15 ( $4 \mathrm{~g})$ in absolute ethanol $(30 \mathrm{~mL})$. The mixture solution was refluxed for $12 \mathrm{~h}$. After that, the solid was filtered and washed repeatedly with ice-cold EtOH and dried at room temperature by infrared radiation. The dusty solid obtained was designated as aminobenzamid@ Al-SBA-15 (Scheme 3).

\section{Preparation of Co-aminobenzamid@AI-SBA-15}

In a $50 \mathrm{~mL}$ round-bottomed flask, aminobenzamid@ Al-SBA-15 (0.2 g) was added to the mixture solution of $\mathrm{CoCl}_{2}(0.1 \mathrm{mmol})$ in absolute ethanol $(25 \mathrm{~mL})$. Afterward, this mixture solution was stirred at room temperature for $12 \mathrm{~h}$, the solid was filtered and washed repeatedly with absolute ethanol until the eluent became colorless, and then dried at room temperature by infrared radiation. The light-green solid obtained was designated as Co-aminobenzamid@Al-SBA-15. The above samples were prepared by the strategy shown in Scheme 3.

\section{General procedure for the preparation}

of 2,3-dihydroquinazolin-4(1H)-ones under mild reaction Co-aminobenzamid@Al-SBA-15 as an efficient catalyst was added to an ethanol solution of isatoic anhydride $(1 \mathrm{mmol})$, ammonium acetate $(1.2 \mathrm{mmol})$ or primary aromatic amine $(1.1 \mathrm{mmol})$ and aldehyde $(1.0 \mathrm{mmol})$ were heated in reflux, for desired times. As soon as the complete disappearance of the starting material, as checked by TLC (7:3 n-hexane: ethyl acetate). Then the catalyst was removed by Centrifuging. At that instant, $10 \mathrm{~mL}$ ice water was added and the precipitated product was filtered. At the end of the process, the residue was recrystallized from ethanol to obtain the crude product.

\section{Spectroscopic data for selected compounds}

2-(4-Chlorophenyl)-2,3-dihydroquinazolin-4(1H)-one (4c): m.p. $199-201{ }^{\circ} \mathrm{C}$. FT-IR $\left(\mathrm{KBr}, v_{\max } / \mathrm{cm}^{-1}\right)$ : 3307, 3188, 1657, 1609, 1509, 1484. ${ }^{1} \mathrm{H}$ NMR $(400 \mathrm{MHz}$, DMSO- $\left.d_{6}\right): \delta$ (ppm) $8.28(\mathrm{br}$ s, $1 \mathrm{H}), 7.59(\mathrm{dd}, 1 \mathrm{H}$, $J=8.0 \mathrm{~Hz}, J=1.1 \mathrm{~Hz}), 7.49(\mathrm{~d}, 2 \mathrm{H}, J=8.6 \mathrm{~Hz}), 7.44(\mathrm{~d}, 2 \mathrm{H}$, $J=8.6 \mathrm{~Hz}$ ), 7.26-7.21-7.26 (m, 1H), 7.12 (br s, $1 \mathrm{H}), 6.73$ $(\mathrm{dd}, 1 \mathrm{H}, \mathrm{J}=8.0 \mathrm{~Hz}, \mathrm{~J}=1.1 \mathrm{~Hz}), 6.67-6.80(\mathrm{~m}, 1 \mathrm{H}), 5.74$ (s, 1H). ${ }^{13} \mathrm{C}$ NMR (100 MHz, DMSO-d $\left.\mathrm{d}_{6}\right) \delta \mathrm{ppm}=161.8$, 144.9, 140.1, 131.6, 131.1, 127.7 (2C), 127.5, 126.0, 116.7, 113.2, 113.3, 64.9. HRMS (ESI): $\mathrm{m} / \mathrm{z}[\mathrm{M}+\mathrm{H}]^{+}$calcd for $\mathrm{C}_{14} \mathrm{H}_{11} \mathrm{~N}_{2} \mathrm{OCl}$ : 258.0559; found: 258.0614. Anal. Calcd. For $\mathrm{C}_{14} \mathrm{H}_{11} \mathrm{~N}_{2} \mathrm{OCl}$ : C, 65.00; H, 4.29; N, 10.83. Found: C, 65.22; H, 4.19; N, 10.75.

2-(4-Methoxyphenyl)-2,3-dihydroquinazolin-4(1H)one (4i): m.p. $177-179{ }^{\circ} \mathrm{C}$. FT-IR (KBr, $\left.v_{\max } / \mathrm{cm}^{-1}\right): 3305$, 3179, 3054, 1649, 1612, 1508, 1479, 1251, 1037, 749. ${ }^{1} \mathrm{H}$ NMR (400 MHz, DMSO- $d_{6}$ ): $\delta$ (ppm) 8.18 (br s, 1H), 7.62 (d, $1 \mathrm{H}, J=7.2 \mathrm{~Hz}), 7.44(\mathrm{~d}, 1 \mathrm{H}, J=7.3 \mathrm{~Hz}), 7.31(\mathrm{t}, 2 \mathrm{H}$, $J=8.6 \mathrm{~Hz}), 7.20(\mathrm{t}, 1 \mathrm{H}, J=8.4 \mathrm{~Hz}), 7.05(\mathrm{br} \mathrm{s}, 1 \mathrm{H}), 6.90(\mathrm{~d}$, $2 \mathrm{H}, J=8.6 \mathrm{~Hz}), 6.71(\mathrm{t}, 1 \mathrm{H}, J=7.6 \mathrm{~Hz}), 5.76(\mathrm{~s}, 1 \mathrm{H}), 3.76$ $(\mathrm{s}, 3 \mathrm{H}) .{ }^{13} \mathrm{C}$ NMR $\left(100 \mathrm{MHz}, \mathrm{DMSO}-d_{6}\right) \delta \mathrm{ppm}=163.5$, $158.2,146.7,132.9,132.4,127.9,127.3,116.0,115.1$, 113.7, 113.1, 67.2, 52.9. HRMS (ESI): $\mathrm{m} / \mathrm{z}[\mathrm{M}+\mathrm{H}]^{+}$calcd for $\mathrm{C}_{15} \mathrm{H}_{14} \mathrm{~N}_{2} \mathrm{O}_{2}$ : 254.1055; found 254.1106. Anal. Calcd. For $\mathrm{C}_{15} \mathrm{H}_{14} \mathrm{~N}_{2} \mathrm{O}_{2}$ : C, 70.85; H, 5.55; N, 11.02. Found: $\mathrm{C}$, 70.76; H, 5.59; N, 11.07 .

3-(4-Bromophenyl)-2-(4-nitrophenyl)-2,3-dihydroquinazolin-4(1H)-one (4r) m.p. $237-239{ }^{\circ} \mathrm{C}$. FT-IR $\left(\mathrm{KBr}, v_{\max } / \mathrm{cm}^{-1}\right): 3317,3198,1662,1611,1512,1474$, 762. ${ }^{1} \mathrm{H}$ NMR (400 MHz, DMSO- $\left.d_{6}\right): \delta(\mathrm{ppm}) 8.17(\mathrm{~d}$, $3 \mathrm{H}, J=8 \mathrm{~Hz}$ ), 7.82 (br s, $1 \mathrm{H}), 7.71(\mathrm{~d}, 1 \mathrm{H}, J=8), 7.62(\mathrm{~d}$, $3 \mathrm{H}, J=8 \mathrm{~Hz}), 7.53(\mathrm{~d}, 2 \mathrm{H}, J=8 \mathrm{~Hz}), 7.25$ (t, 2H, $J=12)$, 6.77-6.72 (m, 1H), $6.48(\mathrm{~s}, 1 \mathrm{H}) .{ }^{13} \mathrm{C}$ NMR $(100 \mathrm{MHz}$, $\left.\mathrm{DMSO}-d_{6}\right) \delta \mathrm{ppm}=165.6,161.2,146.3,134.4,132.2$, $129.9,128.2,125.6,122.8,118.1,117.2,116.9,115.3$, 113.6, 68.9, 59.3. HRMS (ESI): $\mathrm{m} / \mathrm{z}[\mathrm{M}+\mathrm{H}]^{+}$calcd for $\mathrm{C}_{20} \mathrm{H}_{14} \mathrm{~N}_{3} \mathrm{O}_{3} \mathrm{Br}$ : 423.0218; found: 423.0262. Anal. calcd. 


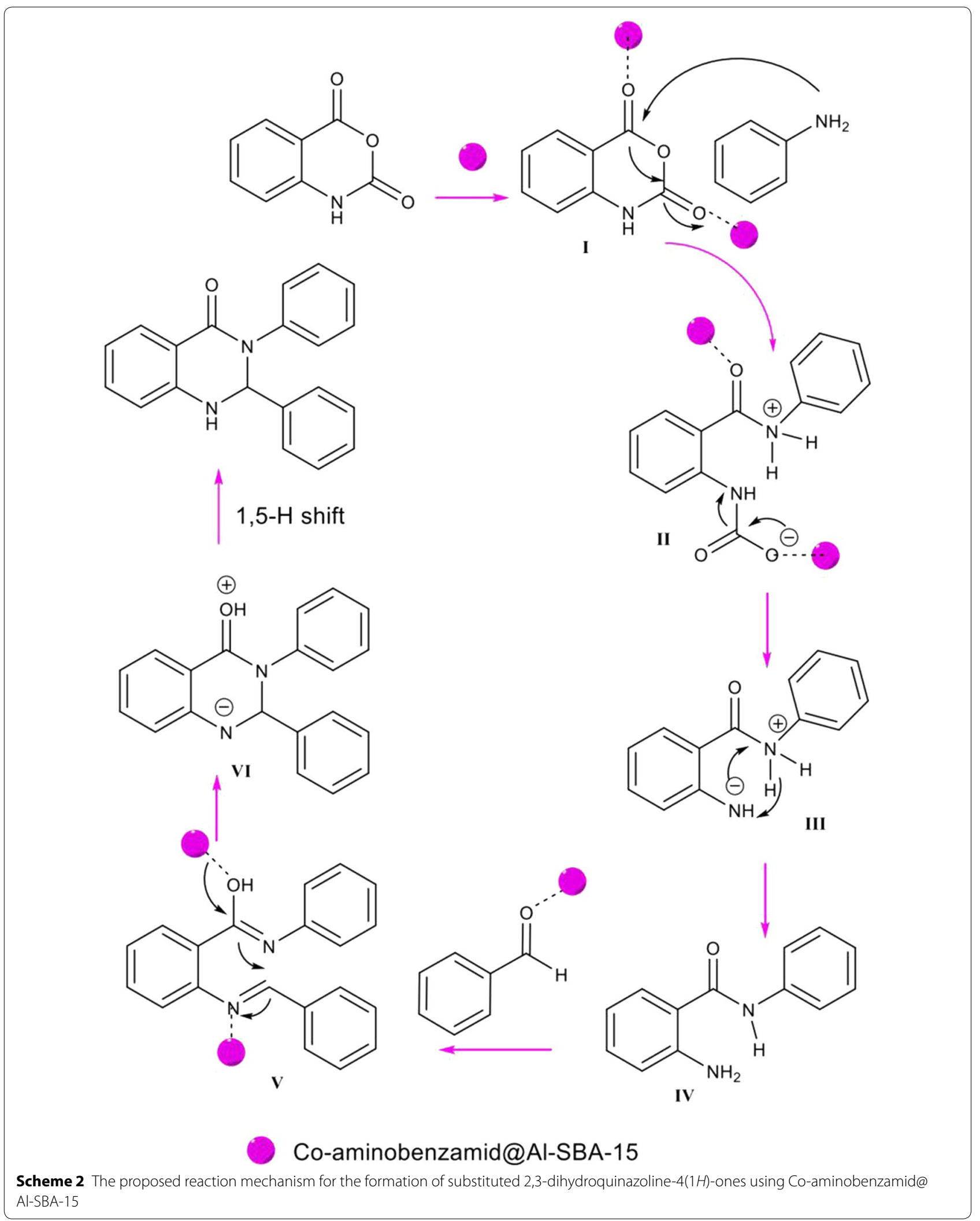




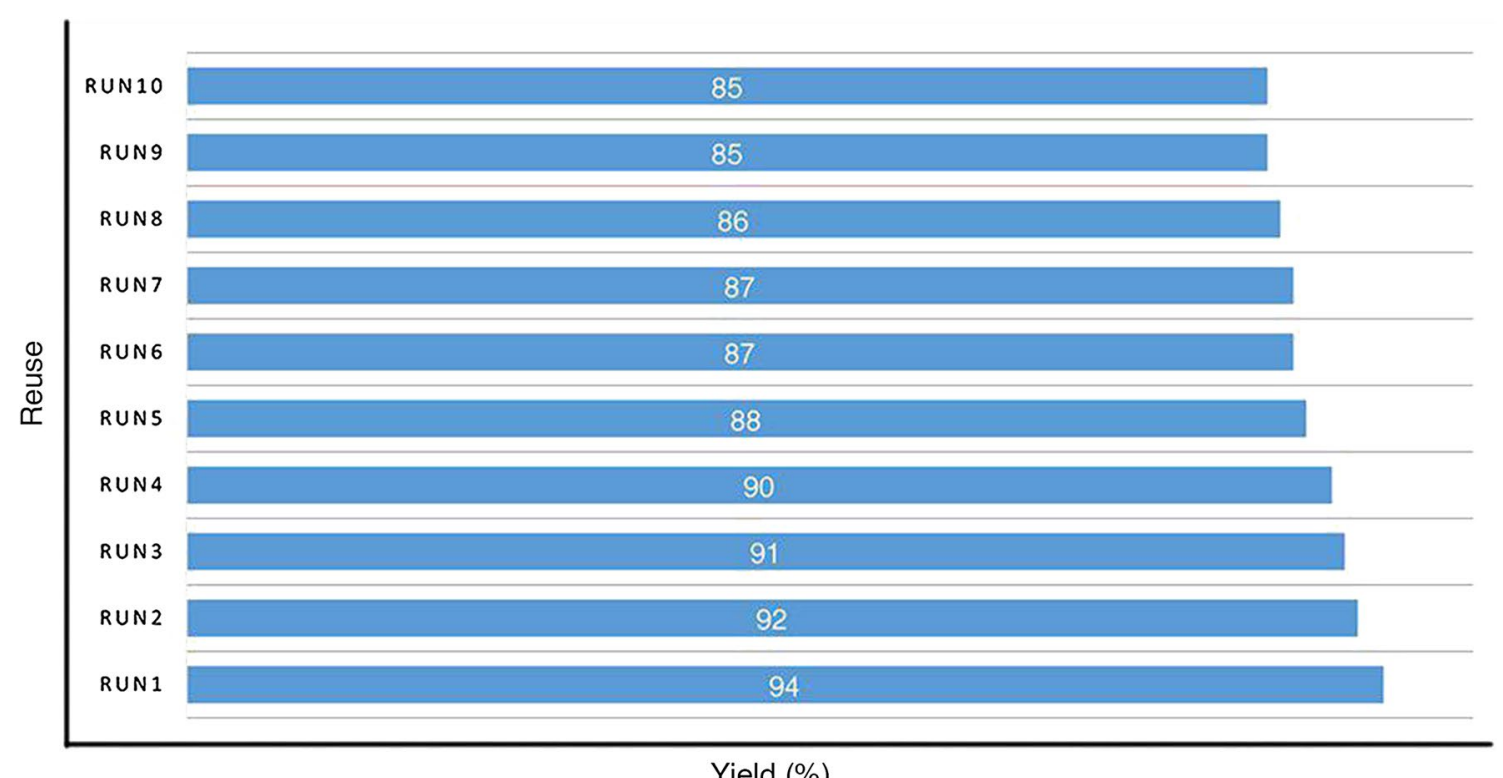

Fig. 6 Reusability of Co-aminobenzamid@Al-SBA-15 for the synthesis of 4k

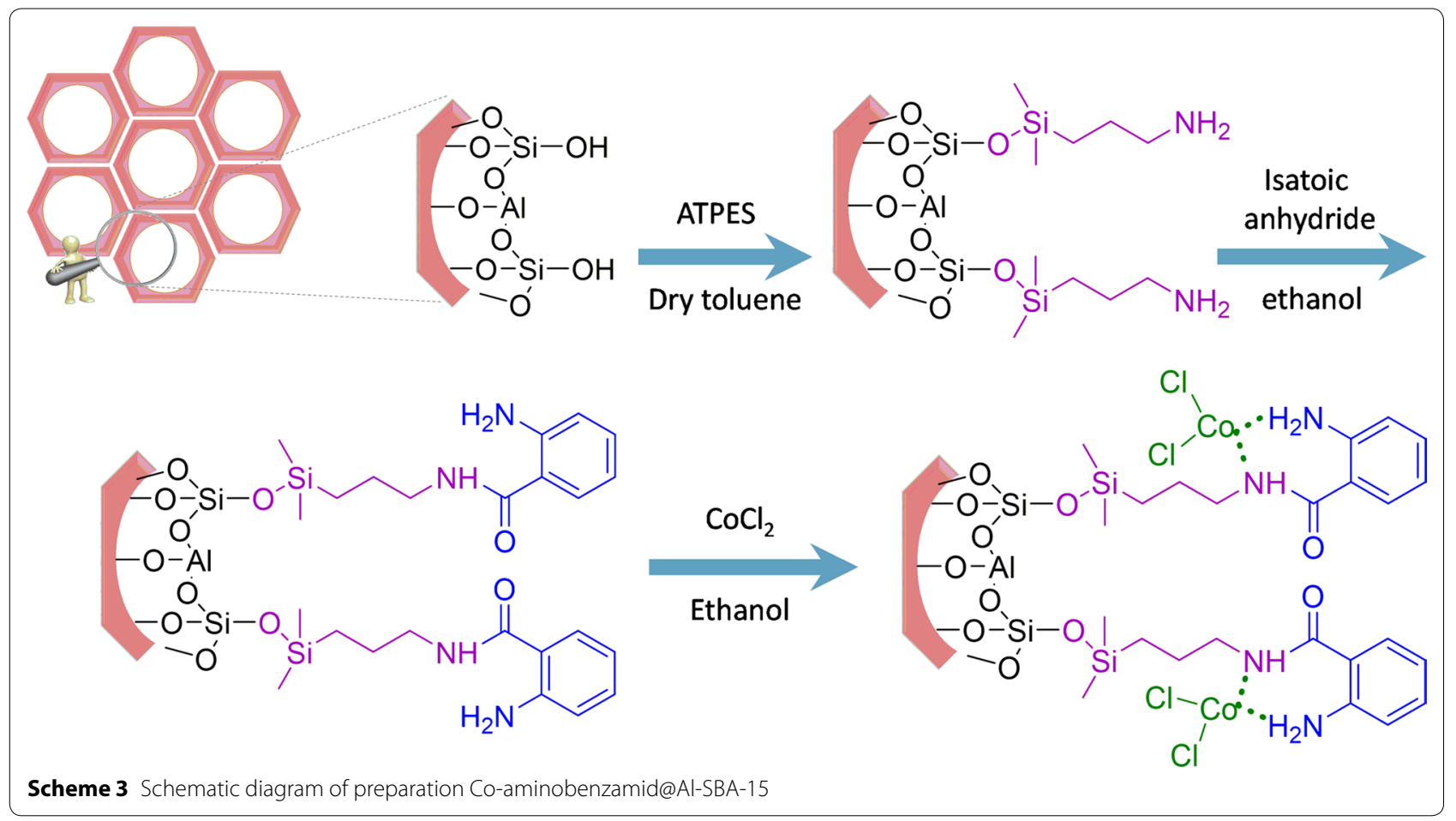

for $\mathrm{C}_{20} \mathrm{H}_{14} \mathrm{~N}_{3} \mathrm{O}_{3} \mathrm{Br}$ : C, 56.73; H, 3.30; N, 9.92, Found: C, $56.58 ; \mathrm{H}, 3.36 ; \mathrm{N}, 9.82$.

3-Benzyl-2-(4-nitrophenyl)-2,3-dihydroquinazolin4(1H)-one (4s) m.p. $191-192{ }^{\circ} \mathrm{C}$. FT-IR (KBr, $v_{\max } /$ $\mathrm{cm}^{-1}$ ): 3412, 3017, 2332, 1592, 1512, 1425, 774. ${ }^{1} \mathrm{H}$ NMR
(400 MHz, DMSO- $\left.d_{6}\right): \delta(\mathrm{ppm}) 8.18(\mathrm{~d}, J=8,1 \mathrm{H}), 7.69(\mathrm{~d}$, $J=8,1 \mathrm{H}), 7.55(\mathrm{~d}, 2 \mathrm{H}, J=8), 7.31-7.20(\mathrm{~m}, 8 \mathrm{H}), 6.72-6.63$ $(\mathrm{m}, 2 \mathrm{H}), 5.95(\mathrm{~d}, 1 \mathrm{H}, J=4 \mathrm{~Hz}), 5.29(\mathrm{~d}, 1 \mathrm{H}, J=12 \mathrm{~Hz})$, $3.96(\mathrm{~d}, J=12 \mathrm{~Hz}, 1 \mathrm{H}) .{ }^{13} \mathrm{C}$ NMR $\left(100 \mathrm{MHz}\right.$, DMSO- $\left.d_{6}\right) \delta$ $\mathrm{ppm}=163.1,148.4,141.1,133.0,132.4,128.5,125.2(2 \mathrm{C})$, 
$123.8,123.2,121.3,117.5,113.9,114.8,114.2,68.1$, 52.7. HRMS (ESI): $\mathrm{m} / \mathrm{z}[\mathrm{M}+\mathrm{H}]^{+}$calcd for $\mathrm{C}_{21} \mathrm{H}_{17} \mathrm{~N}_{3} \mathrm{O}_{3}$ : 359.1269; found: 359.1311. Anal. calcd. for $\mathrm{C}_{21} \mathrm{H}_{17} \mathrm{~N}_{3} \mathrm{O}_{3}$ : C, 68.29; H, 4.60; N, 11.38, Found: C, 68.19; H, 4.51; N, 11.22.

\section{Additional file}

Additional file 1. Additional information.

\section{Authors' contributions}

JSG have designed the study, participated in discussing results and revised the manuscript. RT and AB have designed, carried out the literature study, performed the assay, conducted the optimization, purification of compounds and prepared the manuscript. Furthermore, performed the related analyses. All authors read and approved the final manuscript.

\section{Acknowledgements}

The authors are grateful to university of Kashan for supporting this work by Grant No: 159196/XXII.

\section{Competing interests}

The authors declare that they have no competing interests.

\section{Availability of data and materials}

All data are fully available without restriction.

\section{Associated content}

Experimental procedure and product characterization data: IR, ${ }^{1} \mathrm{H} \mathrm{NMR},{ }^{13} \mathrm{C}$ NMR and elemental analyses of the selected compounds are reported in Additional file 1.

\section{Consent for publication}

The authors declare that the copyright belongs to the journal.

\section{Ethics approval and consent to participate}

Not applicable.

\section{Funding}

Not applicable.

\section{Publisher's Note}

Springer Nature remains neutral with regard to jurisdictional claims in published maps and institutional affiliations.

Received: 22 August 2018 Accepted: 16 January 2019

Published online: 28 February 2019

\section{References}

1. Xu Z, Zhang Y, Fu H, Zhong H, Hong K, Zhu W (2011) Antifungal quinazolinones from marine-derived Bacillus cereus and their preparation. Bioorg Med Chem Lett 21:4005-4007

2. Hour M-J, Huang L-J, Kuo S-C, Xia Y, Bastow K, Nakanishi Y, Hamel E, Lee K-H (2000) 6-Alkylamino-and 2, 3-dihydro-3'-methoxy-2-phenyl-4quinazolinones and related compounds: their synthesis, cytotoxicity, and inhibition of tubulin polymerization. J Med Chem 43:4479-4487

3. Hu Y, Ehli E, Hudziak J, Davies G (2012) Berberine and evodiamine influence serotonin transporter (5-HTT) expression via the 5-HTT-linked polymorphic region. Pharmacogenomics J 12:372-378

4. Cruz-Lopez O, Conejo-García A, Nunez M C, Kimatrai M, E Garcia-Rubino M, Morales F, Gomez-Perez V, M Campos J (2011) Novel substituted quinazolines for potent EGFR tyrosine kinase inhibitors. Curr Med Chem 18:943-963

5. Noel R, Gupta N, Vr Pons, Al Goudet, Garcia-Castillo MD, Al Michau, Martinez J, Buisson D-A, Johannes L, Gillet D (2013) N-methyldihydroquinazolinone derivatives of Retro-2 with enhanced efficacy against Shiga toxin. J Med Chem 56:3404-3413

6. Williams R, Niswender CM, Luo Q, Le U, Conn PJ, Lindsley CW (2009) Positive allosteric modulators of the metabotropic glutamate receptor subtype 4 (mGluR4). Part Il: challenges in hit-to-lead. Bioorg Med Chem Lett 19:962-966

7. Dabiri M, Salehi P, Otokesh S, Baghbanzadeh M, Kozehgary G, Mohammadi AA (2005) Efficient synthesis of mono-and disubstituted 2, 3-dihydroquinazolin-4 $(1 \mathrm{H})$-ones using $\mathrm{KAl}\left(\mathrm{SO}_{4}\right)_{2} 12 \mathrm{H}_{2} \mathrm{O}$ as a reusable catalyst in water and ethanol. Tetrahedron Lett 46:6123-6126

8. Dabiri M, Salehi P, Baghbanzadeh M, Zolfigol MA, Agheb M, Heydari S (2008) Silica sulfuric acid: an efficient reusable heterogeneous catalyst for the synthesis of 2, 3-dihydroquinazolin-4(1H)-ones in water and under solvent-free conditions. Catal Commun 9:785-788

9. Song Z, Liu L, Wang Y, Sun X (2012) Efficient synthesis of mono-and disubstituted 2, 3-dihydroquinazolin-4(1H)-ones using aluminum methanesulfonate as a reusable catalyst. Res Chem Intermed 38:1091-1099

10. Yavari I, Beheshti S (2011) ZnO nanoparticles catalyzed efficient one-pot three-component synthesis of 2, 3-disubstituted quinalolin-4(1H)-ones under solvent-free conditions. J Iran Chem Soc 8:1030-1035

11. Shaterian HR, Oveisi AR, Honarmand M (2010) Synthesis of 2, 3-dihydroquinazoline-4 (1H)-ones. Synth Commun 40:1231-1242

12. Salehi P, Dabiri M, Baghbanzadeh M, Bahramnejad M (2006) One-pot, three component synthesis of 2,3-dihydro-4(1H)-quinazolinones by montmorillonite K-10 as an efficient and reusable catalyst. Synth Commun 36:2287-2292

13. Patil DR, Ingole PG, Singh K, Dalal DS (2013) Inclusion complex of Isatoic anhydride with $\beta$-cyclodextrin and supramolecular one-pot synthesis of 2, 3-dihydroquinazolin-4 (1H)-ones in aqueous media. J Incl Phenom Macrocycl Chem 76:327-332

14. Song Z, Wan X, Zhao S (2012) A novel catalyst cobalt m-nitrobenzenesulfonate-catalyzed highly efficient synthesis of substituted-quinazolin4(1H)-ones. Indian J Chem Technol 19:118-123

15. Kresge CT, Leonowicz ME, Roth WJ, Vartuli JC, Beck JS (1992) Ordered mesoporous molecular sieves synthesized by a liquid-crystal template mechanism. Nature 359:710

16. Beck J, Vartuli J, Roth WJ, Leonowicz M, Kresge C, Schmitt K, Chu C, Olson DH, Sheppard E, McCullen S (1992) A new family of mesoporous molecular sieves prepared with liquid crystal templates. J Am Chem Soc 114:10834-10843

17. Scott BJ, Wirnsberger G, Stucky GD (2001) Mesoporous and mesostructured materials for optical applications. Chem Mater 13:3140-3150

18. Taguchi A, Schüth F (2005) Ordered mesoporous materials in catalysis. Microporous Mesoporous Mater 77:1-45

19. Gracia MD, Balu AM, Campelo JM, Luque R, Marinas JM, Romero AA (2009) Evidences of the in situ generation of highly active Lewis acid species on Zr-SBA-15. Appl Catal 371:85-91

20. Melero JA, Arsuaga JM, de Frutos P, Iglesias J, Sainz J, Blázquez S (2005) Direct synthesis of titanium-substituted mesostructured materials using non-ionic surfactants and titanocene dichloride. Microporous Mesoporous Mater 86:364-373

21. Gedeon A, Lassoued A, Bonardet J, Fraissard J (2001) Surface acidity diagnosis and catalytic activity of AI-SBA materials obtained by direct synthesis. Microporous Mesoporous Mater 44:801-806

22. Bass JD, Katz A (2003) Thermolytic synthesis of imprinted amines in bulk silica. Chem Mater 15:2757-2763

23. Voit B (2006) Sequential one-pot reactions using the concept of "site isolation". Angew Chem Int Ed 45:4238-4240

24. Perozo-Rondón E, Martín-Aranda RM, Casal B, Durán-Valle CJ, Lau WN, Zhang X, Yeung KL (2006) Sonocatalysis in solvent free conditions: an efficient eco-friendly methodology to prepare chalcones using a new type of amino grafted zeolites. Catal Today 114:183-187

25. Safaei-Ghomi J, Nazemzadeh SH, Shahbazi-Alavi H (2016) Preparation and characterization of $\mathrm{Fe}_{3} \mathrm{O}_{4} @ \mathrm{SiO}_{2}$ /APTPOSS core-shell composite nanomagnetics as a novel family of reusable catalysts and their application in the one-pot synthesis of 1, 3-thiazolidin-4-one derivatives. Appl Organomet Chem 30:911-916 
26. Safaei-Ghomi J, Akbarzadeh Z, Ziarati A (2014) A convenient and efficient synthesis of triarylamine derivatives using Cul nanoparticles. RSC Adv 4:16385-16390

27. Chen J, Wu D, He F, Liu M, Wu H, Ding J, Su W (2008) Gallium (III) triflatecatalyzed one-pot selective synthesis of 2, 3-dihydroquinazolin-4 (1H)ones and quinazolin-4 (3H)-ones. Tetrahedron Lett 49:3814-3818

28. Wang M, Zhang TT, Liang Y, Gao JJ (2012) Efficient synthesis of mono-and disubstituted 2, 3-dihydroquinazolin-4 (1H)-ones using copper benzenesulfonate as a reusable catalyst in aqueous solution. Monatsh Chem 143:835-839

29. Razavi N, Akhlaghinia B (2016) Hydroxyapatite nanoparticles (HAP NPs): a green and efficient heterogeneous catalyst for three-component one-pot synthesis of 2, 3-dihydroquinazolin-4(1H)-one derivatives in aqueous media. New J Chem 40:447-457

30. Santra S, Rahman M, Roy A, Majee A, Hajra A (2014) Nano-indium oxide: an efficient catalyst for one-pot synthesis of 2, 3-dihydroquinazolin-4(1H)ones with a greener prospect. Catal Commun 49:52-57

31. Zhao D, Huo Q, Feng J, Chmelka BF, Stucky GD (1998) Nonionic triblock and star diblock copolymer and oligomeric surfactant syntheses of highly ordered, hydrothermally stable, mesoporous silica structures. J Am Chem Soc 120:6024-6036

32. Li Y, Zhang W, Zhang L, Yang Q, Wei Z, Feng Z, Li C (2004) Direct synthesis of Al-SBA-15 mesoporous materials via hydrolysis-controlled approach. J Phys Chem 108:9739-9744
Ready to submit your research? Choose BMC and benefit from:

- fast, convenient online submission

- thorough peer review by experienced researchers in your field

- rapid publication on acceptance

- support for research data, including large and complex data types

- gold Open Access which fosters wider collaboration and increased citations

- maximum visibility for your research: over $100 \mathrm{M}$ website views per year

At BMC, research is always in progress.

Learn more biomedcentral.com/submissions 